\title{
A Mindlin multilayered hybrid-mixed approach for laminated and sandwich structures without shear correction factors
}

\author{
Achraf Tafla* — Rezak Ayad* — Lakhdar Sedira** \\ * Group of Research in Engineering Sciences (GRESPI/LMN EA 4301) \\ University of Reims Champagne-Ardenne \\ ESIEC, Esp. Rolland Garros, BP 1029, F-51686 Reims cedex 2 \\ rezak.ayad@univ-reims.fr \\ ** Mechanical Engineering Laboratory (LGM) \\ Université of Biskra, \\ R Sidi Okba, 07000 Biskra, Algeria
}

\begin{abstract}
A new hybrid-mixed variational approach for the linear analysis of laminated and sandwich plates, without transverse shear correction factors, is presented. It's based on the first order theory of Reissner/Mindlin. A quadratic approximation through the thickness is proposed for transverse shear stresses (continuity $C^{-1}$ ), and two equilibrium equations are used for their approximation. This reduces in consequence the number of interpolation parameters of bending stresses, which are eliminated using the static condensation technique. The proposed approach has been adapted to a quadrilateral 4-node finite element, free of locking, to which performances have been analyzed using some known problems of sandwich and laminated structures.

RÉSUMÉ. Une nouvelle approche variationnelle mixte-hybride, pour l'analyse linéaire des plaques sandwich et stratifiées, sans utilisation de facteurs correctifs du cisaillement transversal (CT), est présentée. Elle est basée sur la théorie du premier ordre de Reissner/Mindlin. Elle propose un champ d'approximation quadratique dans la direction de l'épaisseur pour les contraintes de CT (continuité $C^{-1}$ ), et utilise deux équations d'équilibre pour approcher ces mêmes contraintes en fonction des paramètres d'interpolation des contraintes de flexion, permettant ainsi une réduction des inconnues qui sont éliminées par condensation statique. L'approche proposée est adaptée à un élément fini quadrilatéral à quatre nœuds, dont les performances sont analysées à travers des tests connus de structures stratifiées et sandwich.

KEYWORDS: sandwich plates, laminated plates, finite element, hybrid-mixed model, Reissner/Mindlin, transverse shear.

MOTS-CLÉS: plaques sandwiches, plaques stratifiées, élément fini, modèle mixte-hybride, Reissner/Mindlin, cisaillement transversal.
\end{abstract}

DOI:10.3166/EJCM.19.725-742 @ 2010 Lavoisier, Paris 


\section{Introduction}

Composite materials play a significant role for manufacturing less expensive pieces, with distinguished mechanical properties. The main drawback in using theses materials is the shear effect, it decreases when the number of layers increases. The discontinuity of transverse shear stresses on the interfaces is avoided by imposing continuity conditions on the interfaces. About their finite element modeling, significant efforts have been devoted during the last three decades to the formulation of simple and efficient triangular and quadrilateral finite elements, for the linear and nonlinear analysis of thick and thin isotropic and composite structures. (Zienkiewicz et al., 2005; Hughes et al., 2000; Bathe et al., 1995; Belytschko et al., 2000; Matthews et al., 2000) could be used as some important reading references in the field. A large amount of finite elements have been developed for finite element analysis of laminated composite plates (Zhang et al., 2008). The authors have focused their review on the recently developed laminated finite elements since 1990, from the first order triangular and quadrilateral displacement-based and mixed/hybrid-based finite element models to the higher-order shear deformation theories. Simulating the behavior of multilayered composites often requires of robust finite element models, for obtaining a valid estimation of strains and stresses due to external forces. Most finite elements proposed in the literature are based on the first order model, commonly associated to the Reisnner/Mindlin plate theory, which uses shear correction factors. These elements are generally simple to formulate and less expensive in terms of CPU time. We can cite some interesting references (Song et al., 2002; Auricchio et al., 1999; Nayak et al., 2006; Ayad et al., 2009). To avoid the correction factors, high-order theories have emerged (Tanov et al., 2000; Desai et al., 2003) (Prever et al., 2005) ; with much advantages in terms of the stress accuracy, and some drawbacks, particularly in terms of CPU time, owing to the important number of dof per node involved.

As alternative to the displacement models, the mixed plate bending elements with shear effect have appeared in the mid 1960s. (Herrmann, 1965) has been the first to have attempted proposing a mixed formulation. The mixed elements have been introduced at the end of 1970 s to overcome some difficulties relating to the problems of shear locking and spurious zero-energy modes. The introduction by (Malkus et al., 1978) of the equivalence method between mixed and displacement models allowed to re-interpret a displacement approach in a more general framework of a mixed formulation, in which kinematical and mechanical variables are independently approximated (Simo et al., 1986, Zienkiewicz et al., 1987). Some free of locking triangular and quadrilateral elements have been proposed indeed. More details could be found in (Noor et al., 1982) about the first mixed elements, and in (Ayad et al., 2002, Boffi et al., 2008) about more recent elements. We cite some hybrid-mixed finite element models, used in the literature for composite structures:

- Kim et al., (1998) have used a generalized hybrid-mixed formulation by introducing two bubble functions in the displacement field and in the stress vector 
$(\sigma=P \beta, n(\beta)=9)$. Their model is free of locking and gives good results for the stresses. It is still quite expensive owing to the bubble functions.

- Bishoff et al., (1997) have used a technique called EAS (Enhanced Assumed Strain) to reduce membrane locking and to eliminate sensitivity towards geometric distortion. By this way, 5 or 7 parameters have been introduced for enhancing the membrane deformation field. The ANS method (Assumed Natural Strain) is used to eliminate the shear locking. The authors have used a variational formulation written in the sens of Hu-Washizu.

- Wanmin et al., (1996) proposed a 4-node composite first order element. They used incomplete hybrid-mixed formulation (mixed model for the transverse shear and displacement model for membrane and bending). The authors use "bubble" functions for the rotations and isoparametric functions for linking the bending variables to those of transverse displacement. This element is applied to simulate a delamination problem, where defects occur in the structure.

- A generalization of DKT element has been performed by (Lardeur et al., 1989, 1990 ) in the end of 1980's. A particular ANS (Assumed Natural Strain) method allows defining the shear strains in terms of the rotations $\beta_{x}$ and $\beta_{y}$, by using the bending and shear constitutive equations and two bending moment equilibrium equations. Two finite elements of correct rank, free of locking, have been derived using this technique: The elements DST and DSQ (Discrete Shear Triangle and Quadrilateral) have respectively 9 and 12 dofs.

- Bouabdallah, (1992) used a Hellinger-Reissner mixed formulation. The stresses $\{\sigma\}$ are expressed in terms of parameters $(\alpha)$. At least 14 parameters are needed to perform a mixed model without spurious modes. These parameters are eliminated by static condensation at the elementary level. The derived 4-node quadrilateral mixed element performs well some benchmarks, but still limited to cylindrical structures. On the other hand, it uses the correction factors for simulating the mechanical behaviour of multilayer composite structures

- The element of (Song et al., 2002) is based on a generalized mixed model. The stresses are accurately computed. A linear interpolation is used for the bending moments (M) and the normal efforts $(\mathrm{N})$, with respectively 12 bending parameters $\alpha_{b}$ and 5 membrane parameters $\alpha_{m}$. The approximation of the transverse shear efforts (Q) is defined from bending moments via two equilibrium equations; the same parameters $\alpha_{b}$ appear indeed. To approach the shear deformations $(\gamma)$, the authors assume a constant shear deformation on the element sides. Bilinear interpolations are used for rotations $\beta_{x}$ and $\beta_{y}$ with 4 "bubble" functions. The derived plate element gives good results for displacements and stresses, but must use the correction factors in the shear matrix. It is relatively expensive owing to the "bubble" functions.

Finally, among the elements proposed in the literature, many elements use higher order "bubble" functions (quadratic, cubic and $4^{\text {th }}$ order). Indeed, by this means, the condition of no-locking can be easily verified. The major drawback in the use of such functions is the high cost they generate in terms of integration points. The increase of the approximation parameters, due to the "bubble" functions", may also be a disadvantage, related to the operations of matrix inversion in the process of 
static condensation. We also found that these elements use correction factors in the transverse shear stiffness matrix, once applied to multilayer composite structures.

The finite element we propose in this paper has been developed using a hybridmixed variational approach based on the first order plate theory. A particular quadratic approximation of the transverse shear stresses along thickness direction is used, leading to mixed stiffness matrices without shear correction factors. To eliminate the shear locking problem, the Assumed Natural Strain (ANS) approach, proposed by (Dvorkin et al., 1984; Bathe et al., 1985), has been adopted.

\section{Theoretical formulation of the hybrid-mixed multilayer plate model (MiSP/ml)}

\subsection{Overview of the element MiSP4/ml}

The quadrilateral plate finite element (Figure 1), labelled MiSP4/ml (Mixed with Shear Projection / Multilayer 4-node) (Tafla et al, 2007), is based on the variational model MISP (Mixed Shear Projection) (Ayad et al., 1995; Ayad et al., 2002). It has 4 nodes and 3 dofs per node: one transverse displacement $w$ and two rotations of the normal to the plate mid-surface $\beta_{x}, \beta_{y}$. A bilinear approximation is used for both kinematical variables $\left(w, \beta_{x}, \beta_{y}\right)\left(\mathrm{C}^{\circ}\right.$ continuity) and bending stresses $\left\{\sigma_{l}\right\}\left(\mathrm{C}^{-1}\right.$ continuity). The interpolation of the transverse shear stresses $\{\tau\}$ is derived from that of the bending stresses via two equilibrium equations. Twelve bending and shear parameters are eliminated locally using a static condensation. The ANS method (Assumed Natural Strain) is adopted for a consistent representation of the transverse shear strains along the element sides; this leads to a finite element free of shear locking. Despite being a first order model, MiSP4/ml avoids using shear correction factors by the fact that a particular quadratic interpolation of the transverse shear stresses has been introduced along thickness direction.

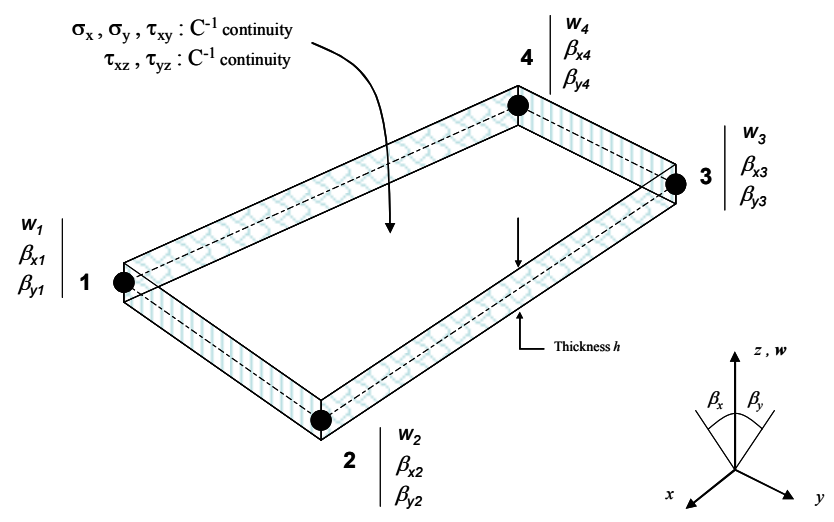

Figure 1. Four-node quadrilateral hybrid-mixed multilayer plate element MiSP4/ml 


\subsection{Variational weak form of the MiSP/ml model}

The variational formulation of the new element (Figure 1) is based on the hybridmixed shear projected model (MiSP). A detailed formulation is given in Reference (Ayad et al., 1998) for the isotropic case. The corresponding variational elementary work, written in Hellinger-Reissner form, is given by

$$
\begin{aligned}
& W_{M i S P / m l}=W_{b}+W_{s}-W_{e x t} \\
& W_{b}=\int_{\mathrm{V}^{\mathrm{e}}}\left(<\varepsilon^{*}>\{\sigma\}+<\sigma^{*}>\{\varepsilon\}-<\sigma^{*}>[\mathrm{H}]^{-1}\{\sigma\}\right) \mathrm{dV} \\
& W_{s}=\int_{\mathrm{V}^{\mathrm{e}}}\left(<\gamma^{*}>\{\tau\}+<\tau^{*}>\{\gamma\}-<\tau^{*}>[\mathrm{G}]^{-1}\{\tau\}\right) \mathrm{dV} \\
& W_{e x t}=\int_{\mathrm{A}^{\mathrm{e}}} w^{*} f_{z} \mathrm{dA}+\int_{\mathrm{S}_{\mathrm{f}}^{\mathrm{e}}}\left(w^{*} \bar{T}_{n}+\beta_{x}^{*} \bar{M}_{x n}+\beta_{y}^{*} \bar{M}_{y n}\right) \mathrm{dA}
\end{aligned}
$$

$W_{b}$ and $W_{s}$ are the internal bending and shear virtual works, $W_{\text {ext }}$ the virtual work of external forces. $w, \beta_{x}, \beta_{y}$ (continuity $\mathrm{C}^{\circ}$ ) are the transverse displacement and the rotations of the normal in the planes $x-z$ and $y-z$ (Figure 1). They are derived from the following displacement variables using the Reissner-Mindlin hypothesis (normal to the mid-surface, before deformation, remains straight after deformation but not necessarily normal):

$$
u=z \beta_{x}(x, y) ; v=z \beta_{y}(x, y) ; w=w(x, y)
$$

The deformations field, relating to the bending and shear of plates, without membrane effects, can be written as,

$$
\begin{aligned}
& \{\varepsilon\}^{T}=\left\langle\varepsilon_{x} \quad \varepsilon_{y} \quad \gamma_{x y}\right\rangle=\zeta\left\langle\varepsilon_{b}\right\rangle ;\left\langle\varepsilon_{b}\right\rangle=\frac{h}{2}\langle\chi\rangle ; z=\frac{h}{2} \zeta \\
& \langle\chi\rangle=\left\langle\begin{array}{lll}
\beta_{x, x} & \beta_{y, y} & \beta_{x, y}+\beta_{y, x}
\end{array}\right\rangle \quad: \quad \text { bending curvatures } \\
& \{\gamma\}^{T}=\left\{\gamma_{0}\right\}^{T}=\left\langle\gamma_{x z} \quad \gamma_{y z}\right\rangle=\left\langle w_{, x}+\beta_{x} \quad w_{, y}+\beta_{y}\right\rangle: z \text {-constant shear strains }
\end{aligned}
$$

NOTE. $-\left\{\gamma_{0}\right\}$ are constant through the thickness. 


\subsection{Approximation of mixed variables}

\subsubsection{Kinematical variables $\left(C^{\circ}\right.$ - continuity)}

A classical bilinear interpolation is adopted for the kinematical variables $w, \beta_{x}, \beta_{y}$ :

$$
\begin{aligned}
& w=\sum_{i=1}^{4} N_{i} w_{i} \quad ; \quad \beta_{x}=\sum_{i=1}^{4} N_{i} \beta_{x i} ; \beta_{y}=\sum_{i=1}^{4} N_{i} \beta_{y i} \\
& N_{i}=\frac{1}{4}\left(1+\xi_{i} \xi\right)\left(1+\eta_{\mathrm{i}} \eta\right) ; \mathrm{i}=1,4 ;-1 \leq \xi \text { et } \eta \leq 1
\end{aligned}
$$

\begin{tabular}{|c|c|c|c|c|}
\hline$i$ & 1 & 2 & 3 & 4 \\
\hline$\xi_{i}$ & -1 & +1 & +1 & -1 \\
\hline$\eta_{i}$ & -1 & -1 & +1 & +1 \\
\hline
\end{tabular}

\subsubsection{Mechanical variables ( $C^{-1}$ - continuity)}

Both weak forms $W_{b}$ and $W_{s}$ (relations [2] and [3]) show the vectors of bending and shear stresses $\{\sigma\}$ and $\{\tau\}$. We have adopted the following choice, showing a quadratic interpolation of the transverse shear stresses through the thickness $(\zeta$ or $z$ ):

$$
\begin{aligned}
& \langle\sigma\rangle=\zeta\left\langle\sigma_{b}\right\rangle \quad ; \quad\left\langle\sigma_{b}\right\rangle=\left\langle\begin{array}{lll}
\sigma_{b x} & \sigma_{b y} & \tau_{b x y}
\end{array}\right) \text { : bending stresses }
\end{aligned}
$$

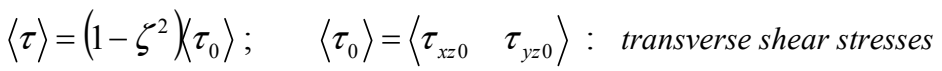

\subsection{Explicit integration along thickness direction}

We perform first of all an explicit integration of form $W_{b}$ [2], applying the interpolations [6] and [11],

$$
\begin{aligned}
W_{b}=\int_{\mathrm{A}^{\mathrm{e}}} \frac{h}{3}<\varepsilon_{\mathrm{b}}^{*}>\left\{\sigma_{\mathrm{b}}\right\} \mathrm{d} \mathrm{A} & +\int_{\mathrm{A}^{\mathrm{e}}} \frac{h}{3}<\sigma_{\mathrm{b}}^{*}>\left\{\varepsilon_{b}\right\} \mathrm{dA} \\
& -\int_{\mathrm{A}^{\mathrm{e}}}<\sigma_{b}^{*}>\frac{4}{h^{2}}\left(\int_{-h / 2}^{+h / 2} z^{2}[H]^{-1} d z\right)\left\{\sigma_{1}\right\} d A
\end{aligned}
$$

The « multilayered » aspect of a composite plate is highlighted by integrating the term $\int_{-h / 2}^{+h / 2} z^{2}[H]^{-1} d z$ as follows ( $n c:$ number of layers) 


$$
\int_{-h / 2}^{+h / 2} z^{2}[H]^{-1} d z=\frac{h^{6}}{12^{2}}\left(\frac{z_{2}^{3}-z_{1}^{3}}{3}[H]_{1}+\ldots \frac{z_{n c}^{3}-z_{n c-1}^{3}}{3}[H]_{n c}\right)^{-1}=\frac{h^{6}}{12^{2}} \sum_{i=1}^{n c}\left(\frac{z_{i+1}^{3}-z_{i}^{3}}{3}[H]_{i}\right)^{-1}[
$$

The final written expression of $W_{b}$ is

$$
W_{b}=\int_{\mathrm{A}^{\mathrm{e}}} \frac{h}{3}<\varepsilon_{\mathrm{b}}^{*}>\left\{\sigma_{\mathrm{b}}\right\} \mathrm{dA}+\int_{\mathrm{A}^{\mathrm{e}}} \frac{h}{3}<\sigma_{\mathrm{b}}^{*}>\left\{\varepsilon_{b}\right\} \mathrm{dA}-\frac{h^{4}}{36} \int_{\mathrm{A}^{\mathrm{e}}}<\sigma_{b}^{*}>\left[\bar{H}_{b}\right]\left\{\sigma_{b}\right\} d A
$$

Where $\left[\bar{H}_{b}\right]=\sum_{i=1}^{n c}\left(\frac{z_{i+1}^{3}-z_{i}^{3}}{3}[H]_{i}\right)^{-1}$ (bending multilayered behaviour matrix)

Applying equations [8] and [12], an explicit integration of form $W_{s}$ [3] is performed in a second stage, leading to a new expression which takes into account the multilayered character of a composite plate:

$$
W_{s}=\int_{A^{e}} \frac{2 h}{3}<\gamma_{0}^{*}>\left\{\tau_{0}\right\} d A+\frac{2 h}{3}<\tau_{0}^{*}>\left\{\gamma_{0}\right\} d A-\int_{A^{e}}<\tau_{0}^{*}>\left[\bar{H}_{s}\right]\left\{\tau_{0}\right\} d A
$$

Where $\left[\bar{H}_{s}\right]=\sum_{i=1}^{n c}\left[\left(z_{i+1}-z_{i}\right)+\frac{16}{5 h^{4}}\left(z_{i+1}^{5}-z_{i}^{5}\right)-\frac{8}{3 h^{2}}\left(z_{i+1}^{3}-z_{i}^{3}\right)\right][G]_{i}^{-1}$

NoTE. - $\left[\bar{H}_{s}\right]$ doesn't need shear correction factors for modeling multilayered structures. It's quite different of that given classically in the literature for displacement models and requiring these famous correction factors.

\subsection{Approximation of the deformation field}

\subsubsection{Bending strains}

Using the interpolations [9], writing matrix of bending strain vector $\left\{\varepsilon_{b}\right\}[6]$ leads to following equation:

$$
\begin{aligned}
& \left\{\varepsilon_{b}\right\}=\left[B_{b}\right]\left\{u_{n}\right\} \quad ; \quad\left[B_{b}\right]=\frac{h}{2}\left[\begin{array}{cccc}
0 & N_{i, x} & 0 & \cdots \\
0 & 0 & N_{i, y} & i=1,4 \\
0 & N_{i, y} & N_{i, x} & \cdots
\end{array}\right] \\
& N_{i, x}=j_{11} N_{i, \xi}+j_{21} N_{i, \eta} \quad ; \quad N_{i, y}=j_{21} N_{i, \xi}+j_{22} N_{i, \eta} \\
& \left\langle u_{n}\right\rangle=\left\langle w_{i} \quad \beta_{x i} \quad \beta_{y i} \quad \ldots i=1,4\right\rangle ; j_{11}, j_{12}, j_{21}, j_{22} \text { (inverse jabobian matrix) }
\end{aligned}
$$




\subsubsection{Transverse shear strains}

To control the shear locking problem, an independent approximation of shear deformations has been used. It's based on the projection technique, labelled ANS (Assumed Natural Strain), which has been proposed by (Dvorkin et al., 1984; Bathe et al., 1985):

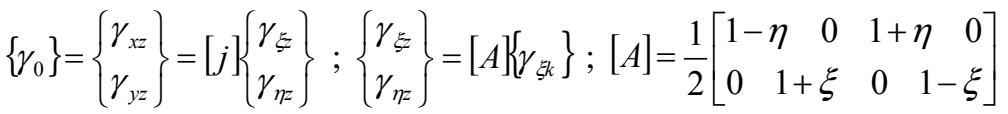

$$
\begin{aligned}
& <\gamma_{\xi k}>=<\gamma_{\xi z}^{A} \quad \gamma_{\eta z}^{B} \quad \gamma_{\xi z}^{C} \quad \gamma_{\eta z}^{D}>\text { (see Figure 2) }
\end{aligned}
$$

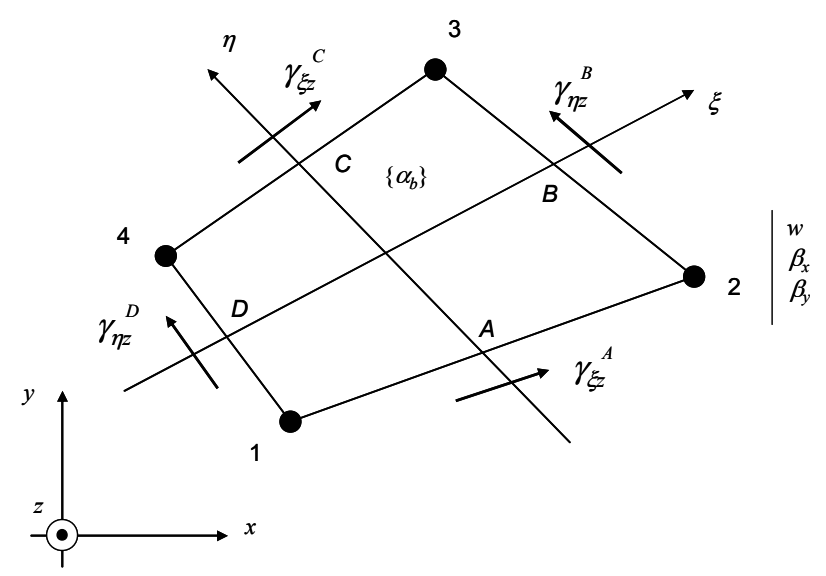

Figure 2. Element MiSP4/ml. Edge projection shear strains

The projection of the edge covariant shear strains $\left\{\gamma_{\xi k}\right\}$ on the element degrees of freedom $\left\{u_{n}\right\}$ becomes necessary. We use indeed two discrete hypothesis of Mindlin defined each one, as follows, on two opposed edges of the element:

$$
\begin{aligned}
& \left.\int_{-1}^{+1}\left(\gamma_{\xi z}-w_{, \xi}-\beta_{\xi}\right) d \xi=0 \quad \text { (sides } 1-2 \text { and } 4-3\right) \\
& \left.\int_{-1}^{+1}\left(\gamma_{\eta_{z}}-w_{, \eta}-\beta_{\eta}\right) d \eta=0 \quad \text { (sides } 2-3 \text { and } 1-4\right) \\
& \left\{\begin{array}{l}
\beta_{\xi} \\
\beta_{\eta}
\end{array}\right\}=[J]\left\{\begin{array}{l}
\beta_{x} \\
\beta_{y}
\end{array}\right\},[J] \text { (Jacobean matrix) }
\end{aligned}
$$

A linear interpolation of rotations $\beta_{\xi}$ and $\beta_{\eta}$, respectively on the two opposed edges $(1-2,4-3)$ and $(1-4,2-3)$, leads to new expressions of relations [24] 


$$
\left\{\gamma_{\xi k}\right\}=\left\{\begin{array}{c}
\gamma_{\xi}^{A} \\
\gamma_{\eta}^{B} \\
\gamma_{\xi}^{C} \\
\gamma_{\eta}^{D}
\end{array}\right\}=\frac{1}{2}\left\{\begin{array}{l}
w_{2}-w_{1}+\beta_{\xi 1}+\beta_{\xi 2} \\
w_{3}-w_{2}+\beta_{\eta 2}+\beta_{\eta 3} \\
w_{3}-w_{4}+\beta_{\xi 3}+\beta_{\xi 4} \\
w_{4}-w_{1}+\beta_{\eta 1}+\beta_{\eta 4}
\end{array}\right\}=\left[B_{s s}\right]\left\{u_{n}\right\}
$$

We lead indeed to the following Cartesian shear vector $\left\{\gamma_{0}\right\}$

$$
\left\{\gamma_{0}\right\}=\left[\bar{B}_{s}\right]\left\{u_{n}\right\} ; \quad\left[\bar{B}_{s}\right]=[j][A]\left[B_{s s}\right]
$$

\subsection{Approximation of the stress field ( $C^{1}$ continuity)}

\subsubsection{Bending stresses}

A bilinear interpolation of real and virtual bending stresses $\left\langle\sigma_{b}\right\rangle$ and $<\sigma_{b}^{*}>$ has been defined as follows

$$
\begin{aligned}
& \left\{\sigma_{b}\right\}=\left[P_{b}\right]\left\{\alpha_{b}\right\} \quad ; \quad\left\{\sigma_{b}^{*}\right\}=\left[P_{b}\right]\left\{\alpha_{b}^{*}\right\} \\
& {\left[P_{b}\right]=\left[\begin{array}{lll}
<p> & <0> & <0> \\
<0> & <p> & <0> \\
<0> & <0> & <p>
\end{array}\right] ; \quad<p>=\left\langle\begin{array}{llll}
1 & \xi & \eta & \xi \eta\rangle \text { (bilinear) }
\end{array}\right.} \\
& \left\{\alpha_{b}\right\}=\left\{\begin{array}{llll}
\alpha_{i} & \ldots & i=1 \text { to } 12\}^{T} \quad \text { (12 bending parameters) }
\end{array}\right.
\end{aligned}
$$

Twelve parameters $\left\{\alpha_{b}\right\}$ are eliminated by static condensation, performed locally at the element level.

\subsubsection{Transverse shear stresses}

The approximation of transverse shear stresses $\left\{\tau_{0}\right\}$ is derived from that of bending stresses $\left\{\sigma_{b}\right\}$ [28], by using two equilibrium equations. We write indeed

$$
\begin{aligned}
& \{\tau\}=\left(1-\zeta^{2}\right)\left\{\tau_{0}\right\}[12] \quad ; \quad\left\{\tau_{0}\right\}=\frac{h}{4} \operatorname{div}\left[\sigma_{b}\right] \\
& \left\{d i v \sigma_{b}\right\}=\left\{\begin{array}{l}
\sigma_{b x, x}+\sigma_{b x y, y} \\
\sigma_{b x y, x}+\sigma_{b y, y}
\end{array}\right\}=\left[P_{s}\right]\left\{\alpha_{b}\right\} \quad ;\left[P_{s}\right]=\left[\begin{array}{ccc}
<p_{1}> & <0> & <p_{2}> \\
<0> & <p_{2}> & <p_{1}>
\end{array}\right] \\
& \left\langle p_{1}\right\rangle=\left\langle\begin{array}{llll}
0 & j_{11} & j_{12} & \eta j_{11}+\xi_{12}
\end{array}\right\rangle \quad ; \quad\left\langle p_{2}\right\rangle=\left\langle\begin{array}{llll}
0 & j_{21} & j_{22} & \eta j_{21}+\xi_{22}
\end{array}\right\rangle
\end{aligned}
$$




\subsection{Hybrid-mixed stiffness matrix for MiSP4/ml}

The bending and shear stress approximations in terms of parameters $\left\{\alpha_{b}\right\}[28$, $31,32]$ and the representation of curvatures $\left\{\varepsilon_{b}\right\}[6,19]$ and shear strains $\left\{\gamma_{0}\right\}[27]$ in terms of nodal variables, lead to following mixed element matrix

$$
\left[k_{\text {mixed }}\right]=\left[\begin{array}{cc}
0 & k_{u b} \\
k_{u b}^{T} & k_{b b}
\end{array}\right]
$$

where

$$
\begin{aligned}
& k_{u b}=\frac{h^{2}}{6} \int_{A^{e}}\left(\left[B_{b}\right]^{T}\left[P_{b}\right]+\left[B_{s}\right]^{T}\left[P_{s}\right]\right) d A \\
& k_{b b}=-\frac{h^{4}}{36} \int_{A^{e}}\left[P_{b}\right]^{T}\left[\bar{H}_{b}\right]\left[P_{b}\right] d A-\frac{h^{2}}{16} \int_{A^{e}}\left[P_{s}\right]^{T}\left[\bar{H}_{s}\right]\left[P_{s}\right] d A
\end{aligned}
$$

After condensation of the 12 parameters $\alpha_{b}$, the final stiffness matrix of the multi-layer hybrid-mixed model MiSP $4 / \mathrm{ml}$ is written as

$$
[k]=\left[k_{u b}\right]^{T}\left[k_{b b}\right]^{-1}\left[k_{u b}\right] \quad(\text { size: } 12 x 12)
$$

$2 \times 2$ gauss points are sufficient for integrating all matrices exactly. The element represents well the three rigid modes. It's free of any shear locking and passes all patch-tests.

\section{Numerical results}

The isotropic version of model MiSP4/ml has been developed and validated by (Ayad et al., 1995). We propose to validate the present multilayer model across some problems known in the literature, involving sandwich and laminated plates. Studies of accuracy on displacements and stresses are mainly performed.

\subsection{Simply supported composite plate under doubly sinusoidal loading}

Two cases of simply supported square laminated plates ( 3 and 9 layers) are submitted to a doubly sinusoidal loading $q$ (Figure 3 ). This problem test has been proposed and studied by (Pagano et al., 1972). The base material is unidirectional strongly orthotropic. Problem's data are described on Figure 3. Two cases of stratification are studied: 


\section{- 3 layers $0 / 90 / 0$}

- 9 layers 0/90/0/90/0/90/0/90/0

In both cases, total thicknesses of layers $0^{\circ}$ and $90^{\circ}$ are equal, and layers of same orientation have all the same thickness. Due to symmetry, only the quarter of plate is modelled using a $6 \times 6$ mesh. Transverse displacement $w$ at point $C$ and shear stresses $\left(\tau_{x z}, \tau_{y z}\right)$ at points $(\mathrm{D}, \mathrm{B})$ are computed using the following dimensionless form:

$$
\begin{aligned}
& \bar{w}_{C}=\frac{\pi^{4} Q}{12 S^{4} h q_{0}} w_{C} ; Q=4 G_{12}+\frac{\left[E_{1}+E_{2}\left(1+2 v_{23}\right)\right]}{\left(1+v_{12} v_{21}\right)} ; S=\frac{L}{h} \\
& \left(\begin{array}{ll}
\bar{\tau}_{x z D} & \bar{\tau}_{y z_{B}}
\end{array}\right)=\frac{1}{q_{0} S}\left(\begin{array}{ll}
\tau_{x z D} & \tau_{y z_{B}}
\end{array}\right)
\end{aligned}
$$
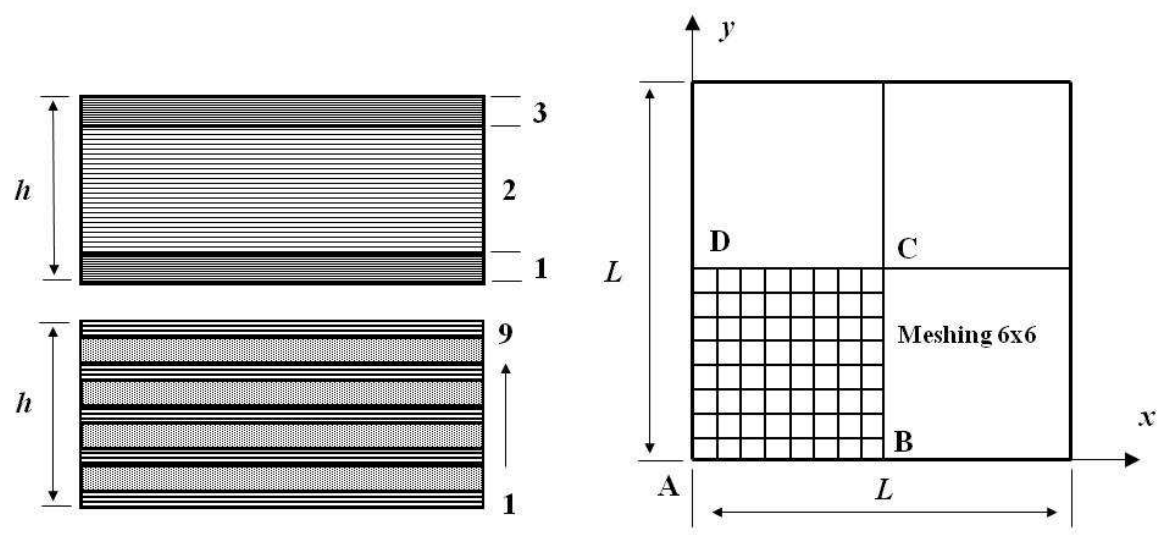

Geometry : $L=1000 \mathrm{~mm}, h=250,100,20,0.1 \mathrm{~mm}$

Material (orthotropic) : $\mathrm{E}_{1} / \mathrm{E}_{2}=\mathbf{2 5}, \mathrm{E}_{2}=10^{6} \mathrm{Psi}, \mathrm{G}_{12}=\mathrm{G}_{13}=0.5 \mathrm{E}_{2}, \mathrm{G}_{23}=0.2 \mathrm{E}_{2}, v_{12}=0.25$

Boundary Conditions : $w=\beta_{x}=0$ on $\mathrm{AB} ; \beta_{x}=0$ on $\mathrm{BC} ; \beta_{y}=0$ on $\mathrm{CD} ; w=\beta_{y}=0$ on DA

Doubly sinusoidal loading: $\quad q=q_{0} \sin \frac{\pi x}{L} \sin \frac{\pi y}{L} \mathrm{~N} / \mathbf{m m}^{2}, \quad q 0=1.0$

Figure 3. Simply supported laminated plate under doubly sinusoidal loading.Data

They are reported, with those of plane stresses, on tables 1 and 2. Also curves of distribution of the stresses $\sigma_{x}$ and $\tau_{x z}$ (for $\mathrm{L} / \mathrm{h}=10$ ) along thickness direction $z$ are respectively displayed in figures 4 and 5 . Values of $\mathrm{E}_{1}, \mathrm{E}_{2}, v_{12}, v_{23}, \mathrm{G}_{12}$, which are respectively the homogenised elastic properties of the composite material, are reported on Figure 3.

Remind that MISP $4 / \mathrm{ml}$ is a multilayer model without shear correction factors. Results of central deflection $w_{C}$ for both cases of stratification, compared with those 
of the element DSQ (Lardeur et al., 1989, 1990) which uses shear correction factors $k_{i}$, are in good agreement with the 3D elastic solution (tables 1 and 2), especially when the ratio L/h is higher (or equal) to 10. On the other hand, like (Pagano et al., 1972) and (Lardeur et al., 1989, 1990), we found that more number of layers is important; less sensitive to the shear effect the structure is.

Results of transverse shear stresses $\tau_{x z}$ at point $\mathrm{D}$ and $\tau_{x z}$ at point $\mathrm{B}$ are quite satisfactory; particularly for $\mathrm{L} / \mathrm{h}=50$ for which computed stresses are close to threedimensional solution. Numerical results of figures 4 and 5 , showing the distribution of in-plane and shear stresses $\sigma_{x}$ and $\tau_{x z}$ through the thickness (for $\mathrm{L} / \mathrm{h}=10$ ), show the good correlation of our model with Pagano's solution. It should be noted that in case of 3-layers $0 / 90 / 0$ (Table $1, \mathrm{~L} / \mathrm{h}=4$ ), results of displacements and stresses away from the solution of Pagano et al. The error decreases from $\mathrm{L} / \mathrm{h}=10$; this explained by a strong presence of transverse shear effect in thick multilayered composite structures. An improvement of MiSP4/ml model, by introducing a higher order displacement (and/or stress), could bring a solution to the problem: a way of development to exploit.

Table 1. Simply supported laminated plate under doubly sinusoidal loading (3-layers). Central deflection and transverse stresses

\begin{tabular}{|c|c|c|c|c|c|c|c|}
\hline $\mathrm{L} / \mathrm{h}$ & FE. Model & $\bar{\tau}_{x z D}$ & $\begin{array}{c}\text { Err } \\
(\%) *\end{array}$ & $\bar{\tau}_{y z B}$ & $\begin{array}{l}\text { Err } \\
(\%)\end{array}$ & $\bar{w}_{C}$ & $\begin{array}{l}\text { Err } \\
(\%)\end{array}$ \\
\hline \multirow{3}{*}{4} & DSQ & 0.245 & 11.9 & 0.331 & -13.3 & 4.834 & -7.6 \\
\hline & $\mathrm{MiSP} 4 / \mathrm{ml}$ & 0.230 & -5.0 & 0.353 & -20.9 & 4.847 & -7.9 \\
\hline & Elasticity* & 0.219 & & 0.292 & & 4.491 & \\
\hline \multirow{3}{*}{10} & DSQ & 0.305 & -1.3 & 0.204 & -4.1 & 1.72 & -0.6 \\
\hline & $\mathrm{MiSP} 4 / \mathrm{ml}$ & 0.302 & -0.3 & 0.208 & -6.1 & 1.771 & -3.6 \\
\hline & Elasticity* & 0.301 & & 0.196 & & 1.709 & \\
\hline \multirow{3}{*}{50} & DSQ & 0.332 & 1.5 & 0.139 & 1.4 & 1.025 & 0.6 \\
\hline & MiSP4/ml & 0.336 & 0.3 & 0.141 & 0 & 1.031 & 0 \\
\hline & Elasticity* & 0.337 & & 0.141 & & 1.031 & \\
\hline \multirow{3}{*}{$10^{4}$} & DSQ & - & - & - & - & - & - \\
\hline & MiSP4/ml & 0.337 & 0.6 & 0,137 & 0.7 & 0.998 & 0.2 \\
\hline & Elasticity* & 0.339 & & 0.138 & & 1.000 & \\
\hline
\end{tabular}

* 3D elastic solution (Pagano et al., 1972) 
Table 2. Simply supported laminated plate under doubly sinusoidal loading (9-layers). Central deflection and stresses at points $C, D$ and $B$

\begin{tabular}{|c|c|c|c|c|c|c|c|c|c|c|c|}
\hline $\mathrm{L} / \mathrm{h}$ & FE. Model & $\begin{array}{l}\bar{\sigma}_{x C} \\
\left(z=\frac{h}{2}\right)\end{array}$ & $\underset{(\%)}{\operatorname{Err}}$ & $\begin{array}{l}\bar{\sigma}_{y C} \\
\left(z=\frac{h}{4}\right)\end{array}$ & $\underset{(\%)}{\operatorname{Err}{ }^{*}}$ & $\begin{array}{l}\bar{\tau}_{x z D} \\
(z=0)\end{array}$ & $\begin{array}{c}E r r \\
* \\
(\%)\end{array}$ & $\begin{array}{l}\bar{\tau}_{y z B} \\
(z=0)\end{array}$ & $\underset{(\%)}{\operatorname{Err}{ }^{*}}$ & $\begin{array}{l}\bar{w}_{C} \\
(z=0)\end{array}$ & $\underset{(\%)}{\operatorname{Err}{ }^{*}}$ \\
\hline \multirow{3}{*}{4} & DSQ & 0.491 & 28.2 & 0.487 & 22.4 & 0.235 & -5.4 & 0.243 & -9.0 & 4.235 & -3.8 \\
\hline & $\mathrm{MiSP} 4 / \mathrm{ml}$ & 0.455 & 33.5 & 0.536 & 14.6 & 0.22 & 1.3 & 0.265 & -18.8 & 4.133 & 1.3 \\
\hline & Elasticity* & 0.684 & & 0.628 & & 0.223 & & 0.223 & & 4.079 & \\
\hline \multirow{3}{*}{10} & DSQ & 0.519 & 5.8 & 0.455 & 4.6 & 0.246 & 0.4 & 0.228 & -0.9 & 1.516 & -0.2 \\
\hline & $\mathrm{MiSP} 4 / \mathrm{ml}$ & 0.505 & 8.3 & 0.476 & 0.2 & 0.242 & 2.0 & 0.237 & -4.9 & 1.512 & 0 \\
\hline & Elasticity* & 0.551 & - & 0.477 & & 0.247 & & 0.226 & & 1.512 & \\
\hline \multirow{3}{*}{50} & DSQ & 0.538 & 0.2 & 0.432 & 0.2 & 0.253 & 1.9 & 0.216 & 1.4 & 1.015 & 0.6 \\
\hline & $\mathrm{MiSP} 4 / \mathrm{ml}$ & 0.54 & -0.2 & 0.435 & -0.4 & 0,256 & 0.8 & 0.218 & 0.4 & 1.019 & 0.2 \\
\hline & Elasticity* & 0.539 & - & 0.433 & & 0.258 & & 0.219 & & 1.021 & \\
\hline \multirow{3}{*}{$10^{4}$} & DSQ & - & - & - & - & - & - & - & - & - & - \\
\hline & $\mathrm{MiSP} 4 / \mathrm{ml}$ & 0.54 & -0.2 & 0.432 & -0.2 & 0.257 & 0.8 & 0.217 & 0.9 & 0.998 & 0.2 \\
\hline & Elasticity* & 0.539 & - & 0.431 & & 0.259 & & 0.219 & & 1.000 & \\
\hline
\end{tabular}

* 3D elastic solution (Pagano et al., 1972)

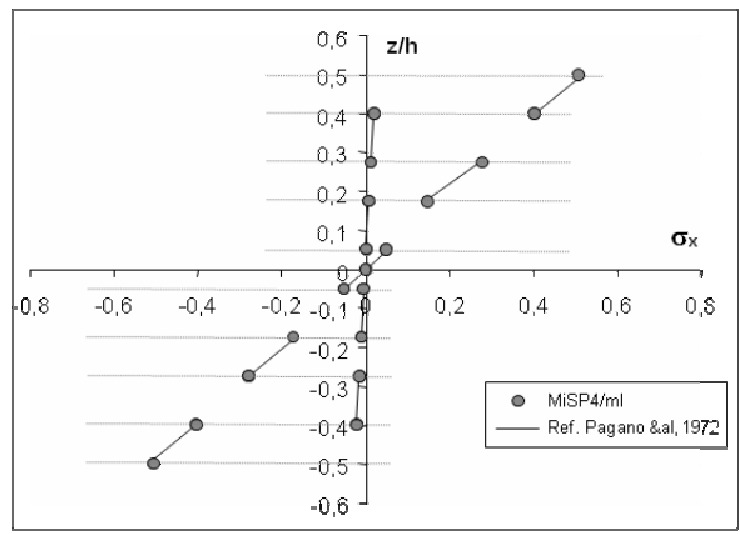

Figure 4. Simply supported laminated plate under doubly sinusoidal loading (9-layers). Distribution of in-plane stress $\sigma_{x}$ along thickness direction $(L / h=10)$ 


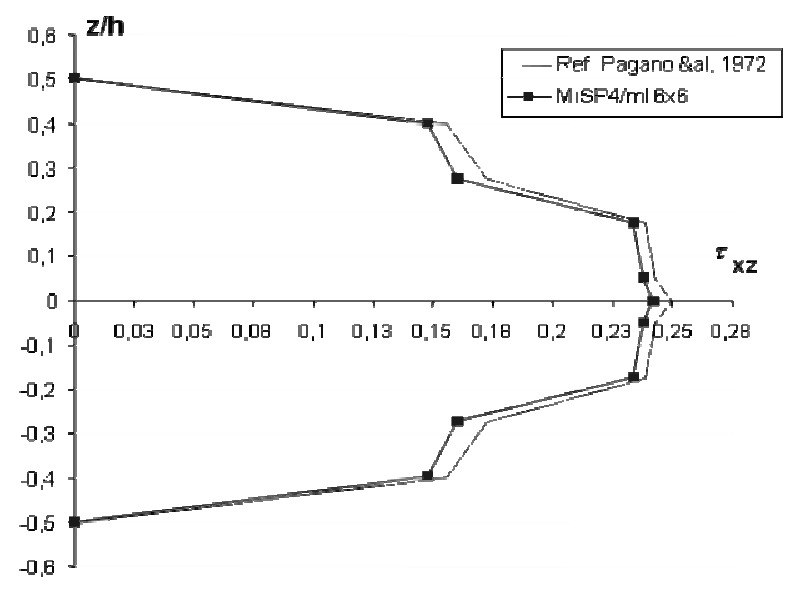

Figure 5. Simply supported laminated plate under doubly sinusoidal loading (9-layers). Distribution of shear stress $\sigma_{x}$ along thickness direction $(L / h=10)$

\subsection{Simply supported sandwich plate under uniform loading.} Comparison with a higher order element

A simply supported square sandwich plate (3-layers) is submitted to a uniform loading $q$ (Figure 6).

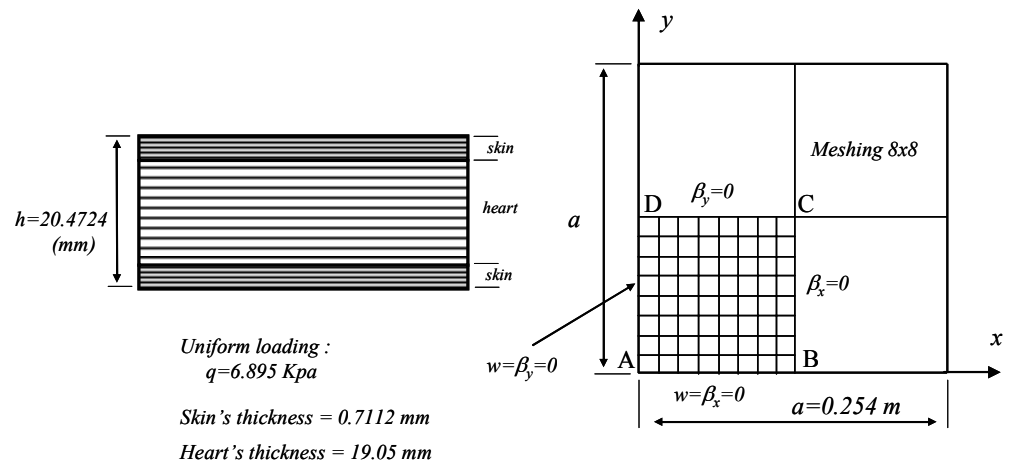

Figure 6. Simply supported sandwich plate under uniform loading. Data

Two types of materials have been studied:

Material 1:

- Skin (isotropic): $E=68.95 \mathrm{GPa}, v=0.3$

- Heart (orthotropic): $E_{x}=E_{y}=6.89510^{-10} \mathrm{MPa}, v_{x y}=0.3, G_{x z}=G_{y z}=206.85 \mathrm{MPa}$ 


\section{Material 2:}

- Skin(isotropic): $E_{x}=68.95 \mathrm{GPa}, E_{y}=27.58 \mathrm{GPa}, v_{x y}=0.3, G_{x y}=12.928125$ $G P a, G_{x z}=G_{y z}=10000 G_{x y}$

- Heart orthotropic: $E_{x}=E_{y}=6.89510^{-10} \mathrm{Mpa}, v_{x y}=0.3, G_{x z}=206.85 \mathrm{MPa}$,

$G_{y z}=82.74 \mathrm{MPa}$

The sandwich has been analysed using a mesh division of $8 \times 8$. Results of our model MiSP $4 / \mathrm{ml}$ are confronted with those of a higher-order model, named RHSDT (Refined Higher-order Shear Deformation Theory) (Topdar et al., 2003). This uses a cubic function to approximate the displacement field in the direction $z$. It has 4 nodes and 7 dofs per node: $u, v, w, \beta_{x}, \beta_{y}, \phi_{x}, \phi_{y}$ ( $\phi_{x}, \phi_{y}$ are warpage rotations). The continuity conditions at the interfaces are thus satisfied. The model RHSDT provides a nonlinear approximation of the shear deformation field at layer level; that allows it to be applied successfully to sandwich panels.

Central deflection of the plate $w_{C}$ and the moment resultant $M_{C}$ of the bending moments $M_{x}, M_{y}, M_{x y}$, have been computed (table 3 ). They have been compared to the reference solutions, obtained by (Plantema et al., 1966) for material 1 and by (Azar et al., 1968) for material 2. Our results are in a good agreement with the reference solutions, as the higher-order model RHSDT.

Table 3. Simply supported sandwich plate under uniform loading sous chargement. Central displacement $w_{C}$ and resultant moment $M_{C}$

\begin{tabular}{|c|c|c|c|c|c|}
\hline \multirow{3}{*}{ Material } & FE. Model & $\begin{array}{c}w_{C} \times 10^{4} \\
(\mathrm{~cm})\end{array}$ & $\begin{array}{c}\text { Err. } \\
(\%)\end{array}$ & $M_{C}{ }^{*}(\mathrm{Nm} / \mathrm{m})$ & $\begin{array}{c}\text { Err. } \\
(\%)\end{array}$ \\
\hline \multirow{3}{*}{ Material 1 } & MiSP4/ml & 20.5 & -9.14 & 21.69 & -1.82 \\
\cline { 2 - 6 } & $\begin{array}{c}\text { Ref. Solution (Plantema } \text { et } \\
\text { al., 1966) }\end{array}$ & 18.79 & -0.04 & 21.30 & 0.047 \\
\hline \multirow{3}{*}{ Material 2 } & Misp4/ml & 33.5 & -7.58 & 34.07 & \\
\cline { 2 - 6 } & \begin{tabular}{c} 
RHSDT \\
\cline { 2 - 6 }
\end{tabular} & 31.01 & 0.408 & 33.42 & \\
\cline { 2 - 6 } & Ref. Solution (Azar et al., & 31.14 & & & \\
\hline
\end{tabular}

$$
\text { " } M c=\sqrt{M_{x}^{2}+M_{y}^{2}+M_{x y}^{2}}
$$




\section{Conclusions}

In the present work, a new hybrid-mixed variational approach, for the analysis of laminated and sandwich plates, based on the first order theory (Reissner/Mindlin), is presented and evaluated. The corresponding quadrilateral finite element model (MiSP4/ml: Mixed with Shear Projection 4-node / multilayer) has 3 dofs per node, and doesn't use correction factors for defining the homogenized behavior of the shear stiffness matrix. A simple quadratic approximation through the thickness is proposed for transverse shear stresses (continuity $\mathrm{C}^{-1}$ ), two equilibrium equations are used for their approximation from that of bending stresses, initially interpolated with bilinear functions; reducing in consequence the number of interpolation parameters. The static condensation eliminates only twelve parameters, optimizing in consequence the CPU time. No bubble functions used, making the model easy to formulate.

MiSP $4 / \mathrm{ml}$ passes successfully all kinematic and mechanical patch-tests and performs well on many testing composite plate problems (Tafla et al., 2007). It should be noted that for some cases of sandwich panels, particularly when $L / h$ is close to 3D situations, the present first order model remains less accurate and requires probably a higher order interpolation of the displacement field.

\section{References}

Auricchio F., Sacco E., "A mixed-enhanced finite-element for the analysis of laminated composite plates", International Journal for Numerical Methods in Engineering, vol. 44, $\mathrm{n}^{\circ} 10,1999$, p. 1481-1504.

Ayad R., Talbi N., Ghomari T., "Modified discrete Mindlin hypothesises for laminated composite structures", Composites Sciences and Technology, vol. 69, 2009, p. 125-128.

Ayad R., Batoz J.L., Dhatt G., « Un élément quadrilatéral de plaque basé sur une formulation mixte-hybride avec projection en cisaillement », Revue Européenne des Eléments Finis, vol. 4, 1995, p. 415-440.

Ayad R., Dhatt G., Batoz J.L., “A new hybrid-mixed variational approach for ReissnerMindlin plates. The MiSP model", International Journal for Numerical Methods in Engineering, vol. 42, 1998, p. 1149-1179.

Azar J.J., "Bending Theory for Multilayer Orthotropic Sandwich Plates", AIAA Journal, vol. 6, 1968., p. 2166-2169.

Bathe K.J., Dvorkin E.N., "A four-node plate bending element based on Mindlin/Reissner plate theory and a mixed interpolation", International Journal for Numerical Methods in Engineering, vol. 21, 1985, p. 367-383.

Bathe K.J., Finite element procedures, Prentice Hall, 1995.

Belytschko T., Moran B., Liu W.K., Nonlinear finite elements for continua and structures, John Wiley \& Sons Inc, 2000. 
Bishoff M., Ramm E., "Shear deformable shell element for large strains and rotation", International Journal for Numerical Methods In Engineering, vol. 40, 1997, p. 4427-4449.

Boffi D., Brezzi F., Demkowicz L.F., Durán R.G., Falk R.S., Fortin M., "Mixed Finite Elements, Compatibility Conditions, and Applications", Lecture Notes in Mathematics, C.I.M.E, Firenze, vol. 1939, 2008.

Bouabdallah M.S., Modélisation de coques cylindriques raidies, isotropes et composites, Thèse de doctorat, Université de Technologie de Compiègne, 1992.

Cen S., Long Y., Yao Z., "A new hybrid enhanced displacement based element for the analysis of laminated composite plate", Compurers and Structures, vol. 80, 2002, p. 819-833.

Desai Y.M., Ramtekkar G.S., Shah A.H., "Dynamic analysis of laminated composite plates using a layer-wise mixed finite element model", Composite Structures, vol. 59, 2003, p. $237-249$.

Dvorkin E.N., Bathe K.J., “A continuum mechanics based four-node shell element for general non-linear analysis", Engineering Computations, vol. 1, 1984, p. 77-88.

Herrman L.R., "A bending analysis for plates", Proceedings of the $1^{\text {st }}$ Conference on Matrix Methods in Stuctural Mechanics, Ohio, 1965, USA, p. 577-602.

Hughes T.J.R, The finite element method: linear static and dynamic finite element analysis, Dover Publications, 2000.

Kim J.G., Kim Y.Y., “A new higher-order hybrid-mixed curved beam element”, International Journal for Numerical Method in Engineering, vol. 43, 1998, p. 925-940.

Lardeur P., Batoz J.L., "Composite plate analysis using a new discrete shear triangular finite element", International Journal for Numerical Methods In Engineering, vol. 27, 1989, p. 343-360.

Lardeur P., Développement et évaluation de deux nouveaux éléments finis de plaques et coques composites avec influence du cisaillement transversal, Thèse de doctorat, Université de Technologie de Compiègne, 1990.

Malkus D.S., Hughes T.J.R., "Mixed finite element methods-reduced and selective integration techniques: a uniform of concepts", Computer Methods in Applied Mechanics and Engineering, vol. 15, 1978, p. 63-81.

Matthews F.L., Davies G.A.O., Hitching D., Soutis C., Finite element modelling of composite materials and structures, Wood Publishing Ltd, Abington Hall, Cambridge, 2000.

Nayak A.K., Shenoi R.A., Moy S.S.J., "Transient response of initially stressed composite sandwich plates", Finite Elements in Analysis and Design, vol. 42, 2006, p. 821-836.

Pagano N.J., Hatfield S.J., "Elastic behaviour of multilayered bidirectional composites", AIAA Journal, vol. 10, n 7, 1972, p. 931-933.

Plantema F.J., Sandwich construction; the bending and buckling of sandwich beams, plates, and shells, New York, Wiley, 1966.

Prever T., Seibi A.C., Al-Jahwari F.K.S., "Analysis of thick orthotropic laminated composite plates based on higher order shear deformation theory", Composite Structures, vol. 71, 2005, p. 414-422. 
Simo J.C., Hughes T.J.R., "On the variational foundations of Assumed Strain Methods", Journal of Applied Mechanics, vol. 53, 1986, p. 51-54.

Song C., Yuqiu L., Zhenhan Y., "A new hybrid enhanced displacement based element for the analysis of laminated composite plate", Computer and Structures, vol. 80, 2008, p. 819-833.

Tafla A., Eléments finis mixtes-hybrides naturels sans facteurs correctifs du cisaillement pour les plaques et les coques composites multicouches, Thèse de doctorat, Université de Reims Champagne-Ardenne, 2007.

Tanov R., Tabiei A., "A simple correction to the first -order shear deformation shell finite element formulation", Finite Element in Analysis and Design, vol. 35, 2003, p. 189-197.

Topdar P., Sheikh A.H., Dhang N., "Finite element Analysis of composite an Sandwich Plates Using a Continuous Inter-Laminar Shear Stress Model", Journal of Sandwich Structures And Materials, vol. 5, n³, 2003., p. 207-231.

Wanmin H., Petyt M., "Linear vibration analysis of laminated rectangular plates using the hierarchical finite element method-I, Free Vibration Analysis", Compurers and Structures, vol. 61, n 4, 1996, p. 705-712.

Zhang Yixia X., Yang Chunhui H., "Recent Advances of Finite Elements for Laminated Composite Plates", Recent Patents on Engineerings, vol. 2, n 1, 2008, p. 36-46.

Zienkiewicz O.C., Lefebvre D., "Three field mixed approximation and the plate bending proble", Communications in Applied Numerical Methods, vol. 3, 1987, p. 301-309.

Zienkiewicz O.C., The finite element method for solid and structural mechanics, Elsevier Butterworth-Heinemann, 2005.

Received: May 2010

Accepted: November 2010 